\title{
Dietary quercetin potentiates the antiproliferative effect of interferon-a in hepatocellular carcinoma cells through activation of JAK/STAT pathway signaling by inhibition of SHP2 phosphatase
}

\author{
Ighodaro Igbe ${ }^{1,2, *}$, Xiao-Fei Shen ${ }^{1, *}$, Wei Jiao ${ }^{1}$, Zhe Qiang ${ }^{1}$, Teng Deng ${ }^{1}$, Sheng Li $^{1}$, \\ Wan-Li Liu ${ }^{3}$, Han-Wei Liu ${ }^{4}$, Guo-Lin Zhang ${ }^{1}$ and Fei Wang ${ }^{1}$ \\ ${ }^{1}$ Key Laboratory of Natural Medicine and Clinical Translation, Chengdu Institute of Biology, Chinese Academy of Sciences, \\ Chengdu, China \\ ${ }^{2}$ Department of Pharmacology and Toxicology, Faculty of Pharmacy, University of Benin, Benin City, Nigeria \\ ${ }^{3}$ MOE Key Laboratory of Protein Sciences, Collaborative Innovation Center for Diagnosis and Treatment of Infectious Diseases, \\ School of Life Sciences, Tsinghua University, Beijing, China \\ ${ }^{4}$ Ningbo Entry-Exit Inspection and Quarantine Bureau Technical Center, Ningbo, China \\ *These authors have contributed equally to this work \\ Correspondence to: Fei Wang, email: wangfei@cib.ac.cn
}

Keywords: quercetin; interferon; SHP2; JAK; STAT

Received: March 22, $2017 \quad$ Accepted: November 03, $2017 \quad$ Published: November 20, 2017

Copyright: Igbe et al. This is an open-access article distributed under the terms of the Creative Commons Attribution License 3.0 (CC BY 3.0), which permits unrestricted use, distribution, and reproduction in any medium, provided the original author and source are credited.

\section{ABSTRACT}

Type I interferons (IFN- $/ \beta$ ) have broad and potent immunoregulatory and antiproliferative activities, which are negatively regulated by Src homology domain 2 containing tyrosine phosphatase-2 (SHP-2). Inhibition of SHP2 by small molecules may be a new strategy to enhance the effcacy of type I IFNs. Using an in vitro screening assay for new inhibitors of SHP2 phosphatase, we found that quercetin was a potent inhibitor of SHP2. Computational modeling showed that quercetin exhibited an orientation favorable to nucleophilic attack in the phosphatase domain of SHP2. Quercetin enhanced the phosphorylation of signal transducer and activator of transcription proteins 1 (STAT1) and promoted endogenous IFN-a-regulated gene expression. Furthermore, quercetin also sensitized the antiproliferative effect of IFN-a on hepatocellular carcinoma HepG2 and Huh7 cells. The overexpression of SHP2 attenuated the effect of quercetin on IFN-a-stimulated STAT1 phosphorylation and antiproliferative effect, whereas the inhibition of SHP2 promoted the effect of quercetin on IFN-a-induced STAT1 phosphorylation and antiproliferative effect. The results suggested that quercetin potentiated the inhibitory effect of IFN-a on cancer cell proliferation through activation of JAK/STAT pathway signaling by inhibiting SHP2. Quercetin warrants further investigation as a novel therapeutic method to enhance the efficacy of IFN-a/ $\beta$.

\section{INTRODUCTION}

Type 1 interferons including IFN- $\alpha$ and IFN- $\beta$ are a family of cytokines which induce and activate the Janus kinase/signal transducer and activator of transcription (JAK/STAT) pathway resulting in their antiviral, antiproliferative, and antitumor activities as well as regulate the activity of the immune system [1]. Several negative regulators of JAKs and STATs participate in the attenuation of JAK/STAT pathway signaling, including Src homology domain 2 containing tyrosine phosphatase-1/2 (SHP-1/2), suppressor of cytokine 
signaling (SOCS) family members, protein inhibitor of activated STAT family members, and the ubiquitin/26S proteasome pathway [2]. Type I IFNs have been used clinically to treat a variety of cancers and viral diseases; however, several serious side effects such as hepatic and hematologic toxicities are related to IFNs therapy. The dose and duration of IFNs therapy also appears to be related to the severity of these side effects [3]. Recently, cell-based ISRE luciferase reporter screening identified several small molecules that were able to modulate the JAK/STAT signaling via various mechanisms, leading to their inhibition of proliferation and viral replication [4-6]. Therefore, the identification of novel bioactive molecues that can enhance or imitate the actions of type I IFNs by inhibition of the negative regulators of JAK/STAT pathway will lead to new methods being developed for treatment of various diseases using IFNs, thus allowing the administration of decreased IFN dosage and the subsequent alleviation of its side effects.

SHP2, encoded by PTPN11, is a first identified oncogenic tyrosine phosphatase [7] that been linked to several genetic, developmental diseases such as Noonan syndrome and multiple cancers including leukemia, lung, and breast cancer, and neuroblastoma [8]. SHP2 is expressed in most tissues and play a regulatory role in cell survival and proliferation by activating the RAS-ERK signaling pathway [9], and is involved in the programmed cell death 1 (PD-1) and B- and T-lymphocyte attenuator (BTLA) immune checkpoint pathways [10]. Furthermore, SHP2 also plays a key role in the negative regulation of the IFN-induced JAK/STAT pathway [11]. In SHP2 knockout mouse fibroblasts, treatment with IFN- $\gamma$ and IFN- $\alpha$ resulted in elevated tyrosine phosphorylation of STAT1 and STAT2 and augmented the suppression of cell viability [12]. SHP2 regulates STAT1 activity mainly by blocking of JAK tyrosine kinase activity and the dephosphorylation of STAT1 at both the tyrosine and serine residues [13]. The inhibition of SHP2 activity suppressed tumor growth and has been an emerging target of cancer treatment [7-9]. Small molecules have been found to inhibit SHP2 activity; however, their efficacy in the enhancement of type I IFN signaling is still unclear.

The abundance of flavonoids in vegetables and fruits contributes to their importance in the reduction of the risk of many chronic diseases [14]. However, their influence on the JAK/STAT pathway, the dominant anticancer and antiviral system in human body, is rarely studied. Quercetin (3, 3', 4', 5, 7-pentahydroxylflavone) is the most abundant flavonoid in the human diet and it is present at high concentrations in onions, apples, red wine, and a variety of berries [15]. Previous studies have shown that quercetin specifically exerted antineoplastic activity through an influence on proliferation, differentiation, and apoptosis in a variety of tumor cell types, including liver cancer $[16,17]$. Mechanismly, quercetin modulated several signal transduction pathways involving MEK/ERK, NF- $\kappa \mathrm{B}, \mathrm{Nrf2} / \mathrm{keap} 1, \mathrm{PI} 3 \mathrm{~K} / \mathrm{Akt} / \mathrm{mTOR}$, and Wnt/ $\beta$-catenin, which are associated with the processes of inflammation and carcinogenesis [18]. However, the pleiotropic actions of quercetin warrants further evaluation of other proteins that may be in the mechanisms of action of quercetin.

Previously, we identified that quercetin increased expression of antiviral genes namely $2^{\prime} 5$ 'oligoadenylate synthetase (2'5'-OAS) and RNA-activated protein kinase (PKR) regulated by type I IFNs by activation of the JAK/ STAT pathway [5]. However, the mechanism of action on the JAK/STAT pathway remains elusive. In the present study, we investigated whether the activation of quercetin on type I IFN-induced JAK/STAT signaling was due to inhibition of SHP2.

\section{RESULTS}

\section{Inhibitory effect of quercetin on SHP2 activity and expression}

By using the recombinantly expressed SHP2 protein, a screening assay was used to screen a natural products based library containing 1431 compounds [5]. After hit reconfirmation, quercetin was shown to significantly inhibit SHP2 activity. The chemical structure of quercetin is shown in Figure 1A. Quercetin showed a concentrationdependent inhibition on the activity of SHP2 with an $\mathrm{IC}_{50}$ value of $10.17 \pm 0.21 \mu \mathrm{M}$ in vitro (Figure $1 \mathrm{~B}$ ). To determine the effect of quercetin on SHP2 activity, HEK293A cells were incubated with quercetin. The cell lysates were then immunoprecipitated with the anti-SHP2 antibody and the activity was determined. Quercetin significantly inhibited SHP2 activity in the treated cells in a concentration-dependent manner compared with the untreated cells (Figure 1C). In addition, quercetin also significantly decreased the protein expression of SHP2 in HepG2 cells in the presence or absence of IFN- $\alpha$ (Figure 1D). In order to know whether quercetin interacted with SHP2 in cells, we performed a cellular thermal shift assay, which is a newly developed method to evaluate drug binding to target proteins in cells [19]. Compared with the DMSO control, the presence of quercetin markedly increased the accumulation of SHP2 in the soluble fraction at the temperatures examined, as shown in Figure 1E. We also tested the concentration-response of quercetin on SHP2 stability at increased temperatures. An increase in quercetin concentration resulted in the markedly increased accumulation of SHP2, as shown in Figure 1F. These data suggested that quercetin interacted directly with SHP2 and inhibited the activity of SHP2 in cells. We further evaluated whether quercetin affects the activity and stability of SHP1. Quercetin inhibited the activity of SHP1 in a concentration-dependent manner with a calculated $\mathrm{IC}_{50}$ value of $31.14 \pm 1.27 \mu \mathrm{M}$ in vitro (Supplementary Figure 1A), and increased the thermal stability of SHP1 (Supplementary Figure 1B). These results suggest that 
quercetin interacted directly with both SHP2 and SHP1 and inhibited the activity of SHP2 more potently than SHP1.

\section{Molecular docking of quercetin with SHP2}

The quercetin binding sites in SHP2 were assessed using computer docking analysis and it was determined that quercetin fitted well in the active site of SHP2 (Figure 2A and 2B). To determine the binding modes of quercetin to the active site of SHP2, the hydrogen-bond (H-bond) formation and hydrophobic interactions between quercetin and the PTP domain of SHP2 were evaluated. There are three polar hydrogens and one carbonyl-oxygen in quercetin that are involved in H-bonding with the $\mathrm{Arg}^{362}, \mathrm{Trp}^{423}, \mathrm{Asp}^{425}, \mathrm{Arg}^{465}$ residues of SHP2 (Figure 2C). Furthermore, quercetin also formed hydrophobic interactions with the residues $\mathrm{Tyr}^{279}, \mathrm{Ile}^{282}, \mathrm{Trp}^{423}, \mathrm{Asp}^{425}$, $\mathrm{His}^{426}, \mathrm{Gly}^{427}, \mathrm{Ser}^{460}, \mathrm{Gly}^{464}, \mathrm{Arg}^{465}, \mathrm{Gln}^{506}$, and $\mathrm{Gln}^{510}$ in the PTP domain (Figure 2D), which may also contribute to its inhibition of the phosphatase activity of SHP2. These results suggested that the orientation/conformation exhibited by quercetin in the PTP domain of SHP2 allowed it to be subjected to nucleophilic attack.

\section{Quercetin enhances type I IFNs-induced activation of JAK/STAT pathway}

Due to the immense role of SHP2 in the negatively modulating the JAK/STAT pathway signaling, we hypothesized that the inhibition of SHP2 by quercetin will lead to enhanced activation of the JAK/STAT pathway. To test this hypothesis, we initially evaluated the effect of quercetin on IFN- $\alpha$-induced JAK/STAT signaling. Treatment with only quercetin produced no obvious effect on the tyrosine phosphorylation of STAT1 in HepG2 cells, but significantly promoted tyrosine phosphorylation of STAT1 in the presence of IFN- $\alpha$ (Supplementary Figure 2 ), which indicated that the activation of the JAK/STAT signaling may be required for quercetin to exert its promotive effect. We then examined the effect of quercetin on the activation of JAKs and STATs in the presence of IFN- $\alpha$. Compared with only IFN- $\alpha$, quercetin enhanced the tyrosine phosphorylation of Jak1 and Tyk2 induced by IFN- $\alpha$ (Figure 3A). Thereafter, the effect of quercetin on the phosphorylation of STAT1, STAT2, and STAT3 in the presence of IFN- $\alpha$ was evaluated. Compared to IFN- $\alpha$ alone, quercetin significantly enhanced the tyrosine phosphorylation of STAT1, but had no significant effect on the tyrosine phosphorylation of STAT2 and STAT3 (Figure 3B). Quercetin also promoted the tyrosine phosphorylation of STAT1 in a time-dependent manner (Figure 3C). Moreover, quercetin obviously elevated IFN- $\beta$-induced tyrosine phosphorylation of STAT1 (Figure 3D), but not STAT3 (Figure 3E). These results suggested that quercetin enhanced the activation of type I IFNs-induced JAK/
STAT pathway. Interestingly, tyrosine phosphorylation of STAT1 (Supplementary Figure 3A) but not STAT3 (Supplementary Figure 3B) could be remarkably enhanced by quercetin treatment in the presence of IFN- $\gamma$, indicating that quercetin also boosted the activation of type II IFNinduced signaling.

\section{Quercetin promotes downstream genes expression induced by IFN- $\alpha$}

To examine whether quercetin can increase downstream gene expression induced by IFN- $\alpha$, we first assessed the effect of quercetin on ISRE reporter expression. In Figure 4A, quercetin significantly promoted ISRE reporter expression in the presence of IFN- $\alpha$, compared with IFN- $\alpha$ alone, in a dose-dependent manner. Furthermore, IFN- $\alpha$ alone or IFN- $\alpha$ plus quercetin treatment for $24 \mathrm{~h}$, did not affect the cell viability of HepG2-ISRE-Luc2 cells (Supplementary Figure 4). The mRNA expression of two IFN- $\alpha$ responsive genes, $2^{\prime}, 5^{\prime}$ OAS and PKR, were determined after treatment with various concentrations of quercetin. The mRNA levels of 2',5'-OAS and PKR were significantly increased after treatment with quercetin plus IFN- $\alpha$ compared with only IFN- $\alpha$, as shown in Figure 4B. These results supported our previous results that quercetin enhanced the downstream endogenous gene expression induced by IFN- $\alpha$.

\section{Quercetin enhances the antiproliferative effect of IFN- $\alpha$ on cancer cells}

To determine whether quercetin could sensitize cancer cells to IFN- $\alpha$-induced antiproliferative effect, we treated human hepatoma cancer cells (HepG2 and Huh-7) with quercetin and IFN- $\alpha$. The addition of quercetin (1-10 $\mu \mathrm{M})$ potentiated the antiproliferative effect of IFN- $\alpha$ in a dose-dependent manner (Figure 5A); however, quercetin alone did not affect the cell proliferation at the same concentration (Supplementary Figure 5). Furthermore, quercetin significantly inhibited the colony formation of HepG2 cells in the presence of IFN- $\alpha$ when compared to cells treated with only IFN- $\alpha$ (Figure 5B). In addition, the suppression of IFN- $\alpha$ on cyclin D1 expression was further enhanced by quercetin treatment (Figure 5C). These results suggested that quercetin enhanced IFN- $\alpha$-induced antiproliferative effect in hepatocellular carcinoma cells.

\section{Quercetin promotes IFN- $\alpha$-mediated effects via SHP2 inhibition}

SHP2 negatively regulates the JAK/STAT pathway signaling initiated by type I IFNs through the dephosphorylation of activated JAKs and STATs. Hence, quercetin may target SHP2 to promote the activation of the JAK/STAT pathway. To test this hypothesis, we overexpressed SHP2 in HepG2 cells, which attenuated 
A<smiles>O=c1c(O)c(-c2ccc(O)c(O)c2)oc2cc(O)cc(O)c12</smiles>

C

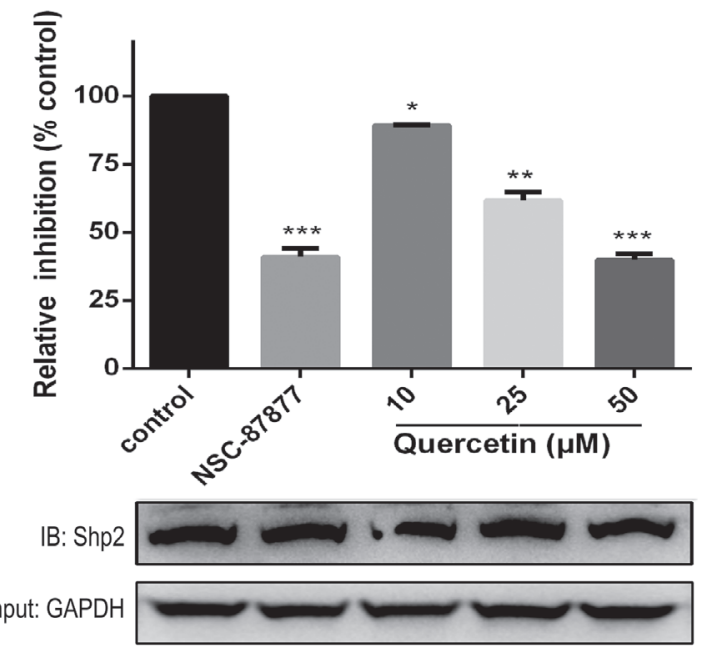

$\mathrm{E}$
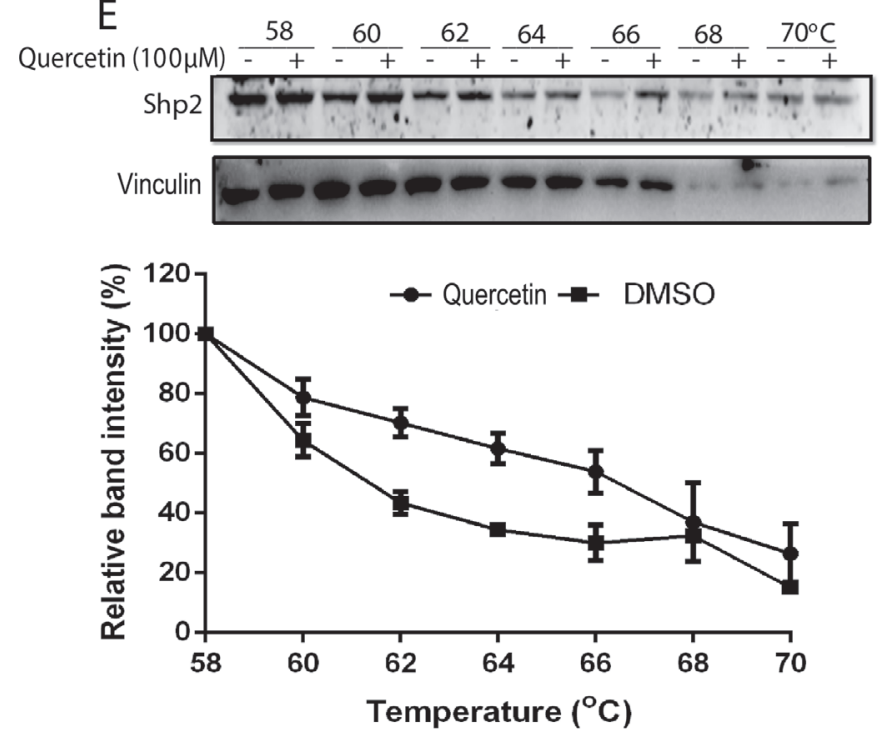

B

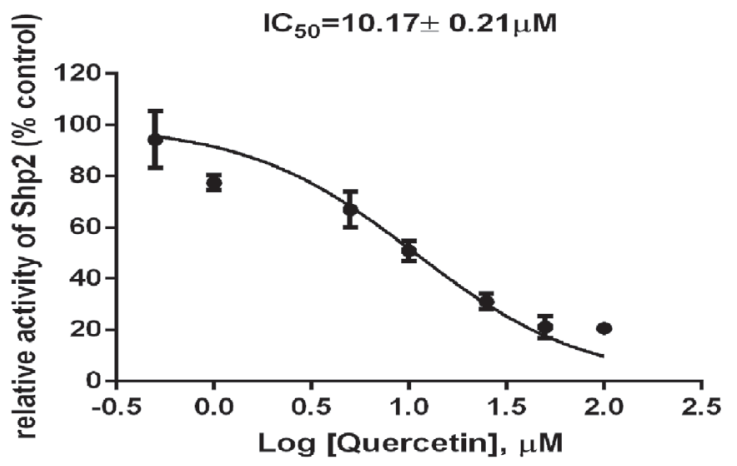

$\mathrm{D}$

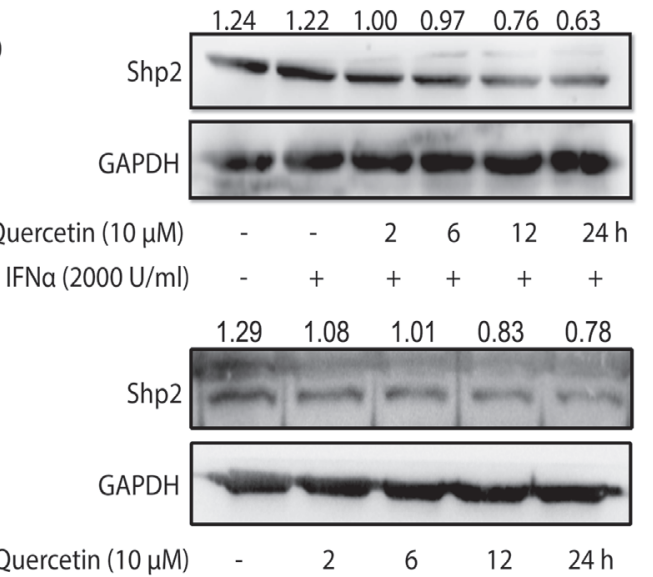

$\mathrm{F}$
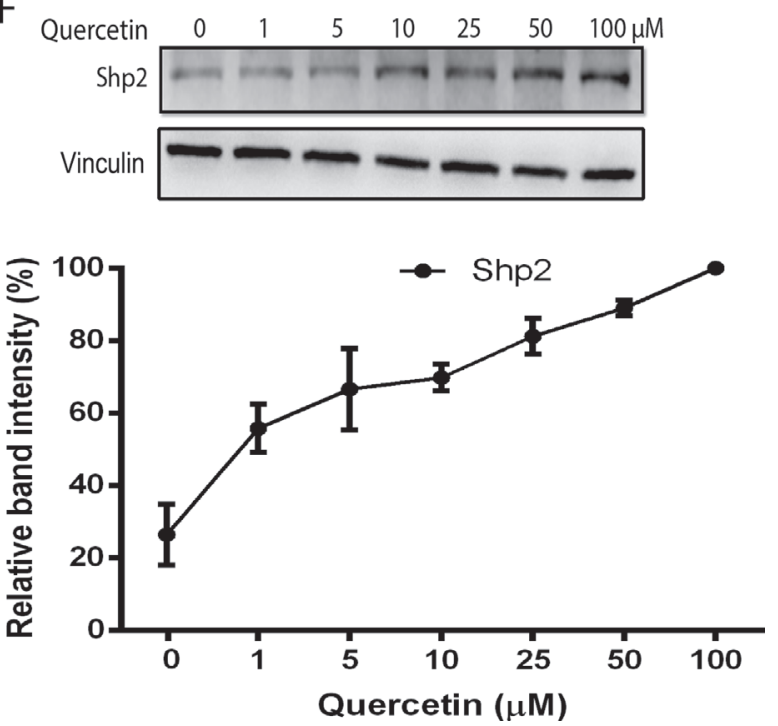

Figure 1: Inhibitory effect and interaction of quercetin with SHP2 activity. (A) The chemical structure of quercetin. (B) DiFMUP substrate was treated with various concentrations of quercetin in the presence of recombinantly expressed SHP2 protein and the $\mathrm{IC}_{50}$ was calculated. (C) HEK293A cells treated with quercetin $(10,25,50 \mu \mathrm{M})$ and SHP2 inhibitor (NSC-87877, $\left.10 \mu \mathrm{M}\right)$ for $6 \mathrm{~h}$ were lysed, immunoprecipitated with anti-SHP2 antibody, and SHP2 activity was determined. Then, the immunoprecipitation products were used to quantify the protein amount of SHP2. GAPDH was used as the input. (D) HepG2 cells were treated with quercetin (10 $\mu$ M) alone for $2,6,12$, and $24 \mathrm{~h}$, or followed by the addition of $2000 \mathrm{U} / \mathrm{mL}$ IFN- $\alpha$ for $30 \mathrm{~min}$. The cell lysates were immunoblotted with the antiSHP2 antibody. GAPDH staining is shown as a loading control. (E, F) The cellular thermal shift assay was performed on HEK293A cells as described in Materials and Methods section. The stabilization effect of quercetin on SHP2 and vinculin at different temperatures (E) and different concentrations (F) was evaluated by western blot. Each experiment was repeated at least three times. Data were expressed as mean \pm S.D., ${ }^{*} p<0.05,{ }^{* *} p<0.01,{ }^{* * *} p<0.001$ vs control. 
the quercetin-induced enhancement of INF- $\alpha$-induced STAT1 phosphorylation in untransfected cells, as shown in Figure 6A. Meanwhile, overexpression of SHP2 partially abolished IFN- $\alpha$ and IFN- $\alpha$ plus quercetininduced ISRE reporter expression in HepG2-ISRE-Luc cells (Figure 6B) and viability of HepG2 cells (Figure $6 C)$. To further confirm the role of SHP2 on quercetinenhanced STAT1 phosphorylation and antiproliferative effect, HepG2 cells were pre-treated with a specific SHP2 inhibitor (NSC-87877). NSC-87877 treatment increased the IFN- $\alpha$-stimulated phosphorylation of STAT1 (Figure $6 \mathrm{D})$, which was further promoted by addition of quercetin (Figure 6E). NSC-87877 treatment had no significant effect on the tyrosine phosphorylation of STAT2 and STAT3 (Supplementary Figure 6). NSC-87877 treatment also increased IFN- $\alpha$-induced anti-proliferative effect on HepG2 cells, which was further promoted by addition of quercetin (Figure 6F). As SOCS1 and SOCS3 are also involved in the negative regulation of JAK activation, the effect of quercetin on SOCS1 and SOCS3 expression was evaluated; the results showed that quercetin had no effect on the expression of SOCS1 and SOCS3 (Supplementary Figure 7). We then examined the effect of quercetin on $26 \mathrm{~S}$ proteasome, another negative regulator of JAK/STAT pathway. As shown in Supplementary Figure 8, quercetin had no inhibitory effect on $26 \mathrm{~S}$ proteasome. These results suggested that quercetin promotes IFN- $\alpha$-induced phosphorylation of STAT1 and antiproliferative effect via SHP2 inhibition.

\section{DISCUSSION}

The upregulation of SHP2 expression has been reported in many human cancers; a decrease in SHP2 activity inhibits tumor cell growth and is a promising target for chemotherapy [8-10]. In our study, we found that quercetin, a naturally occurring flavonoid, was a potent inhibitor of SHP2 catalytic activity and suppressed the expression of SHP2 in hepatocellular carcinoma cells. These results were also supported by the finding that quercetin decreased the expression of SHP2 and subsequently downregulated the activation of epidermal growth factor receptor (EGFR) in HeLa cervical cancer cells [20]. The molecular docking of quercetin to the PTP domain responsible for the phosphatase activity of SHP2 showed that quercetin might suppress the phosphatase activity mainly via hydrogen bonding and hydrophobic interaction. Among the amino acid residues that interacted with quercetin, $\mathrm{Arg}^{362}$ was considered to enhance the interaction of SHP2 with its substrate proteins and thereby aid opening [21]. Asp ${ }^{425}$ acts as a proton donor for the phenolate leaving group of the substrate and an acceptor during the hydrolysis of the cysteinyl phosphate intermediate [22]. $\mathrm{Arg}^{465}$, a key residue of the PTP signature motif $\left(\mathrm{C}^{459}(\mathrm{X})_{5} \mathrm{R}^{465}\right)$, has been associated with the catalysis of SHP2 to stabilize the phosphotyrosine substrate-enzyme complex [23]. NSC-87877, a known SHP2 inhibitor, forms hydrogen bonds with the backbone $\mathrm{NH}$ group of $\mathrm{Arg}^{465}$ in the PTP signature motif and with

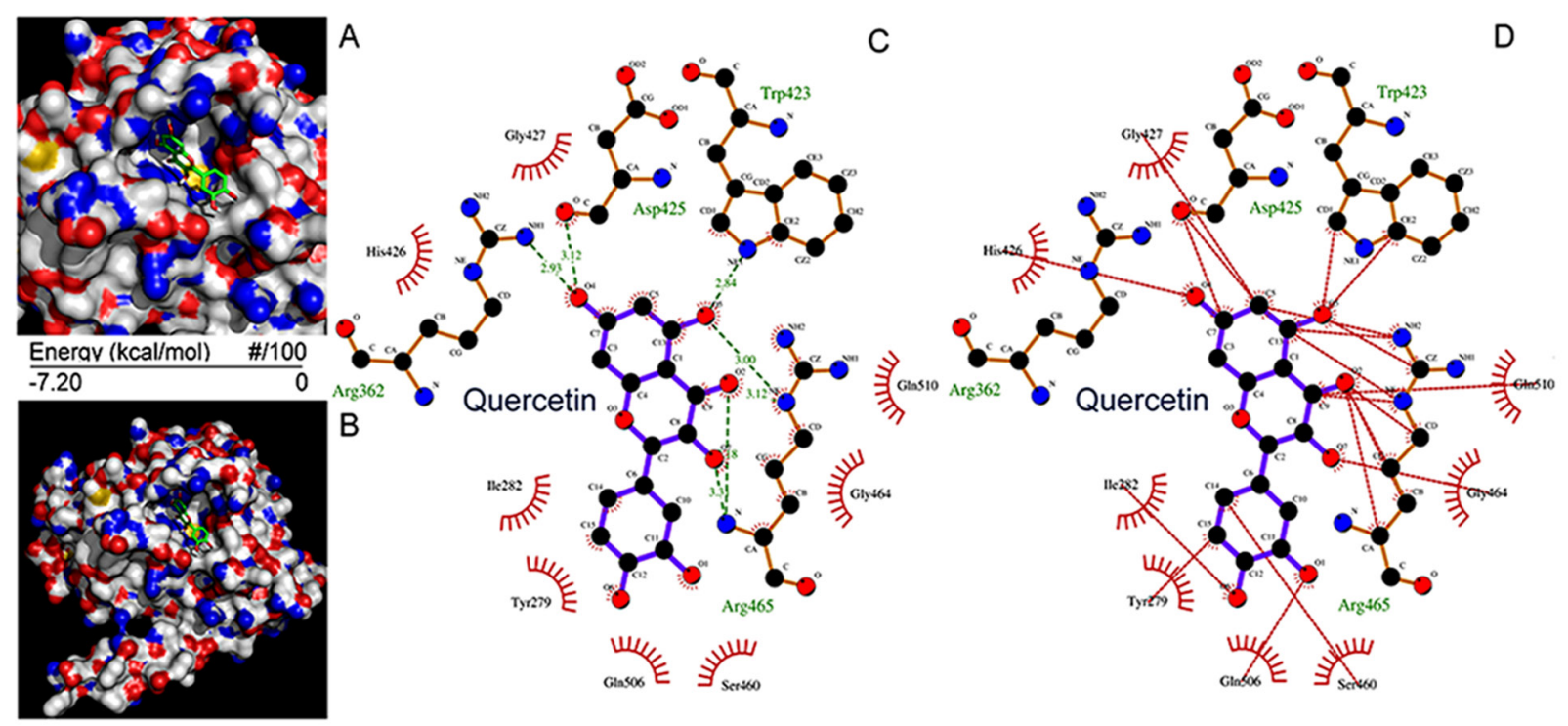

Figure 2: Molecular docking of quercetin on SHP2. (A, B) Quercetin was docked into the SHP2 active site (PTP domain) using Autodock 4.2.6. Quercetin is shown using stick model and the carbon atoms are colored in green. (C, D) The docking scheme of quercetin and SHP2 PTP domain. The hydrogen bonds formed between quercetin and the protein via Arg362, Trp423, Asp425, and Arg465 are highlighted in green dotted lines, while the hydrophobic interactions formed between quercetin and the SHP2 PTP domain via Tyr279, Ile282, Trp423, Asp425, His426, Gly427, Ser460, Gly464, Arg465, Gln506, and Gln510 are highlighted in red dotted lines. 

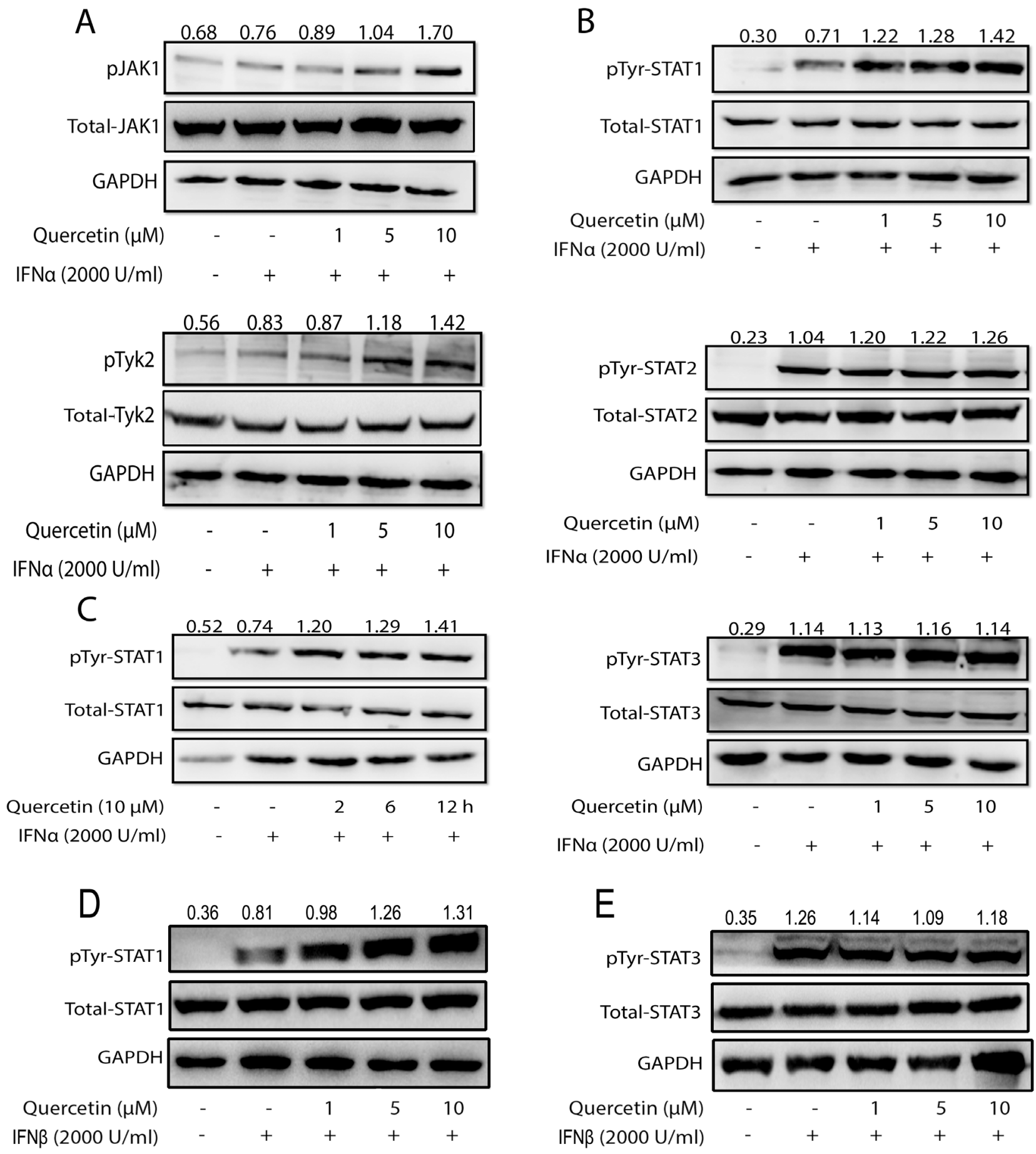

Figure 3: Quercetin enhances IFN $\boldsymbol{\alpha}$-induced JAK/STAT pathway activation. (A, B) HepG2 cells grown in six-well plates were treated with quercetin $(1,5$, or $10 \mu \mathrm{M})$ for $6 \mathrm{~h}$, followed by the addition of $2000 \mathrm{U} / \mathrm{mL}$ IFN- $\alpha$ for 30 min. The cell lysates were immunoblotted with phospho-JAK1 (Tyr1022/1023), phospho-Tyk2 (Tyr1054/1055) antibodies, phospho-STAT1 (Tyr701), phosphoSTAT2 (Tyr690), phospho-STAT3 (Tyr705) antibodies, JAK1, Tyk2, STAT1, STAT2, and STAT3 antibodies. GAPDH staining is shown as a loading control. (C) HepG2 cells were treated with quercetin $(10 \mu \mathrm{M})$ for 2,6 , and $12 \mathrm{~h}$, followed by the addition of $2000 \mathrm{U} / \mathrm{mL}$ IFN- $\alpha$ for $30 \mathrm{~min}$. The cell lysates were immunoblotted with phospho-STAT1 (Tyr701) or STAT1. GAPDH staining is shown as a loading control. (D, E) HepG2 cells were treated with quercetin $(10 \mu \mathrm{M})$ for 2,6 , and $12 \mathrm{~h}$, followed by the addition of $2000 \mathrm{U} / \mathrm{mL}$ IFN- $\beta$ for $30 \mathrm{~min}$. The cell lysates were immunoblotted with phospho-STAT1 (Tyr701) and phospho-STAT3 (Tyr705). GAPDH staining is shown as a loading control. 
the side chains of Lys $^{280}$ and $\mathrm{Asn}^{281}$ [24], which are similar to the amino acids predicted for quercetin. Therefore, it is likely that quercetin inhibited the phosphatase activity of SHP2 by forming hydrogen bonds with the key amino acid residues of the PTP domain, including $\operatorname{Arg}^{362}, \operatorname{Trp}^{423}$, $\mathrm{Asp}^{425}$, and $\mathrm{Arg}^{465}$. Furthermore, some mutations of SHP2, including Tyr279Cys, Ile282Val, and Gln510Glu, have been reported to be involved in the incidence of Noonan syndrome [25]. Quercetin is predicted to be able to form hydrophobic interactions with these amino acids, which suggested that quercetin may inhibit the phosphatase activity of SHP2 by forming hydrophobic interactions with these key amino acid residues of PTP domain. Many dietary flavonoids share a similar structure with quercetin; therefore, it will be of interest to perform further investigations into the structure-activity relationship of flavonoids for the inhibition of SHP2, which may allow the development of new SHP2 inhibitors.

The majority of the current antiviral drugs usually exert their effect by interacting with viral proteins, however, they become less effective with usage due to genetic changes in the viruses [26]. Since, the JAK/STAT pathway plays an important role in antiviral defense and proliferation in human cells, it becomes a promising target for research into novel antiviral and antitumor drugs. Although there is abundance of natural compounds that inhibit the JAK/STAT signaling pathway, information on compounds that activate this pathway is still insufficient [27]. Our results showed that quercetin enhanced IFN$\alpha$-induced JAK/STAT pathway and thereby boosting the antiproliferative effect of IFN- $\alpha$. These results were consistent with our previous report, which showed that quercetin activated the JAK/STAT pathway and increased mRNA expression of two IFN- $\alpha$ responsive antiviral genes, 2',5'-OAS and PKR [5]. Quercetin activated Jak1 and Tyk2, which led to the observed STAT1 activation, but had no significant effect on the tyrosine phosphorylation of STAT2 and STAT3. STAT1 has been reported as a potential tumor suppressor and regulator of the anti-proliferative/ pro-apoptotic responses in tumor cells [28]. The quercetininduced activation of STAT1 inhibited cell proliferation, which may lead to the observed potentiation of the IFN- $\alpha$ induced antiproliferative effect in HepG2 and Huh7 cells. However, quercetin had no effect on SOCS1/3 and $26 \mathrm{~S}$ proteasome, the key negative regulators of JAK/STAT [29]. Thus, quercetin-activated JAK/STAT signaling is

A
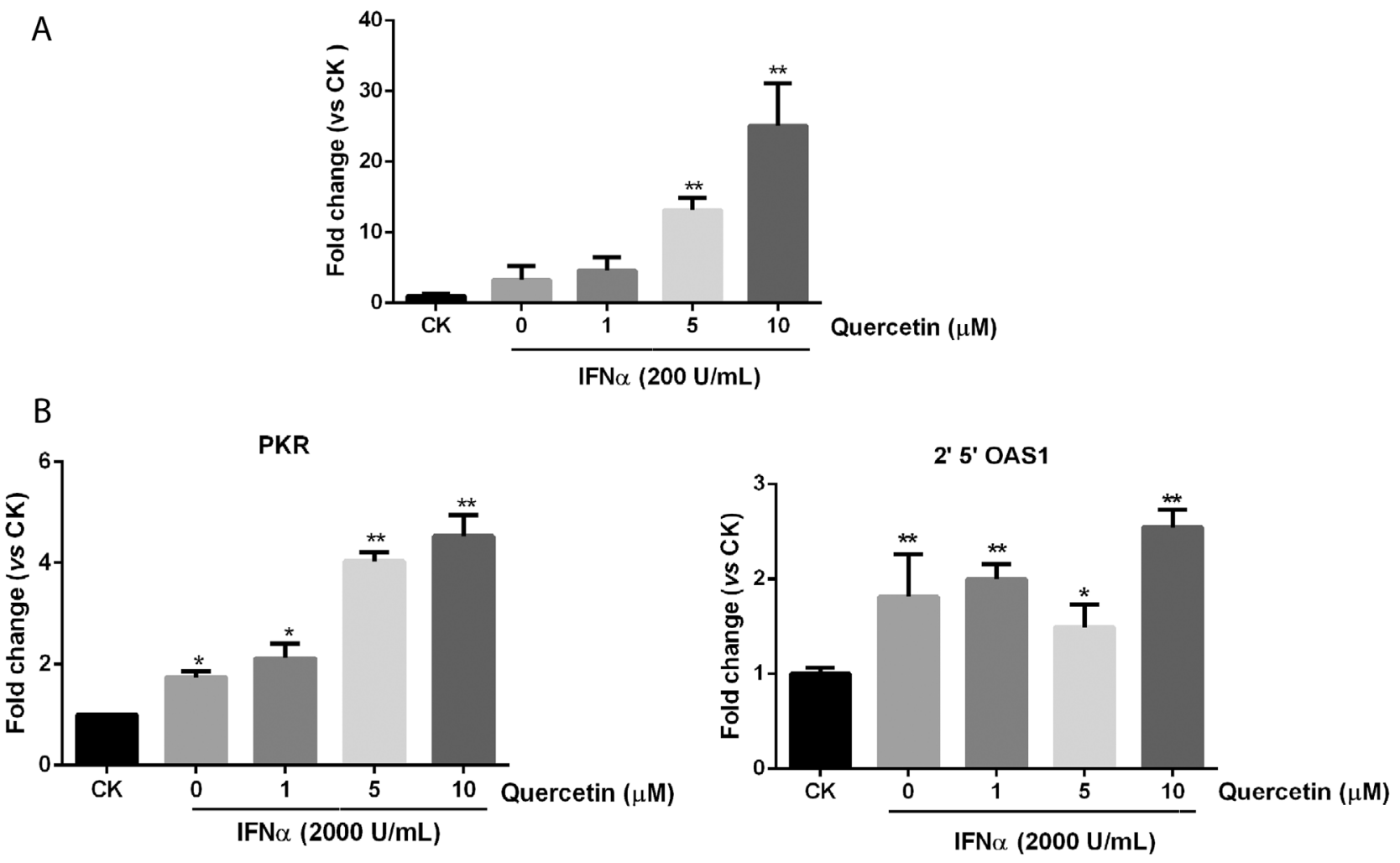

Figure 4: Quercetin promotes downstream genes expression in JAK/STAT pathway. (A) HepG2-ISRE-Luc2 cells were seeded in 96 -well plates $\left(1 \times 10^{4}\right.$ cells/well $)$ and pretreated with various concentrations of quercetin for $2 \mathrm{~h}$ before $200 \mathrm{U} / \mathrm{mL}$ IFN- $\alpha$ was added for a further $24 \mathrm{~h}$. The luciferase activity of the total cell lysate was measured. (B) HepG2 cells were treated with various concentrations

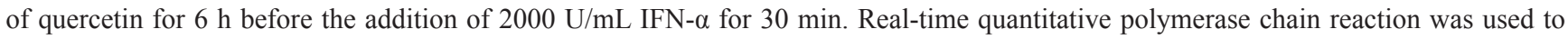
determine the messenger RNA expression of PKR or 2',5'-OAS. The result is presented as induction (n-fold) relative to basal levels in untreated cells. GADPH was used as an internal control. ${ }^{*} p<0.05,{ }^{* *} p<0.01$ vs control; CK, DMSO control. 
probably not mediated by SOCS $1 / 3$ and $26 \mathrm{~S}$ proteasome; instead, it might inactivate a protein phosphatase that dephosphorylates JAKs. In the present study, quercetin was identified as an inhibitor of protein phosphatase SHP2 that causes suppression of the dephosphorylation of Jak1 and Tyk2, which in turn causes the sustained activation of STAT1. SHP2 is also known to dephosphorylate STAT1 at both the tyrosine and serine residues in nuclei [13], therefore, quercetin may inhibit SHP2 to cause direct activation of STAT1. Remarkably, it is relatively easy to increase the plasma concentration of quercetin in human to above $10 \mu \mathrm{M}$, through supplementation with quercetin or quercetin-enriched foods without any significant toxicity effects [30]. Clinically, type I IFNs have been used in the adjuvant setting after resection of human hepatocellular carcinoma [31]. Moreover, SHP2 overexpression is found to enhance liver cancer progression and predict poor prognosis of patients [32]. Based on our results,
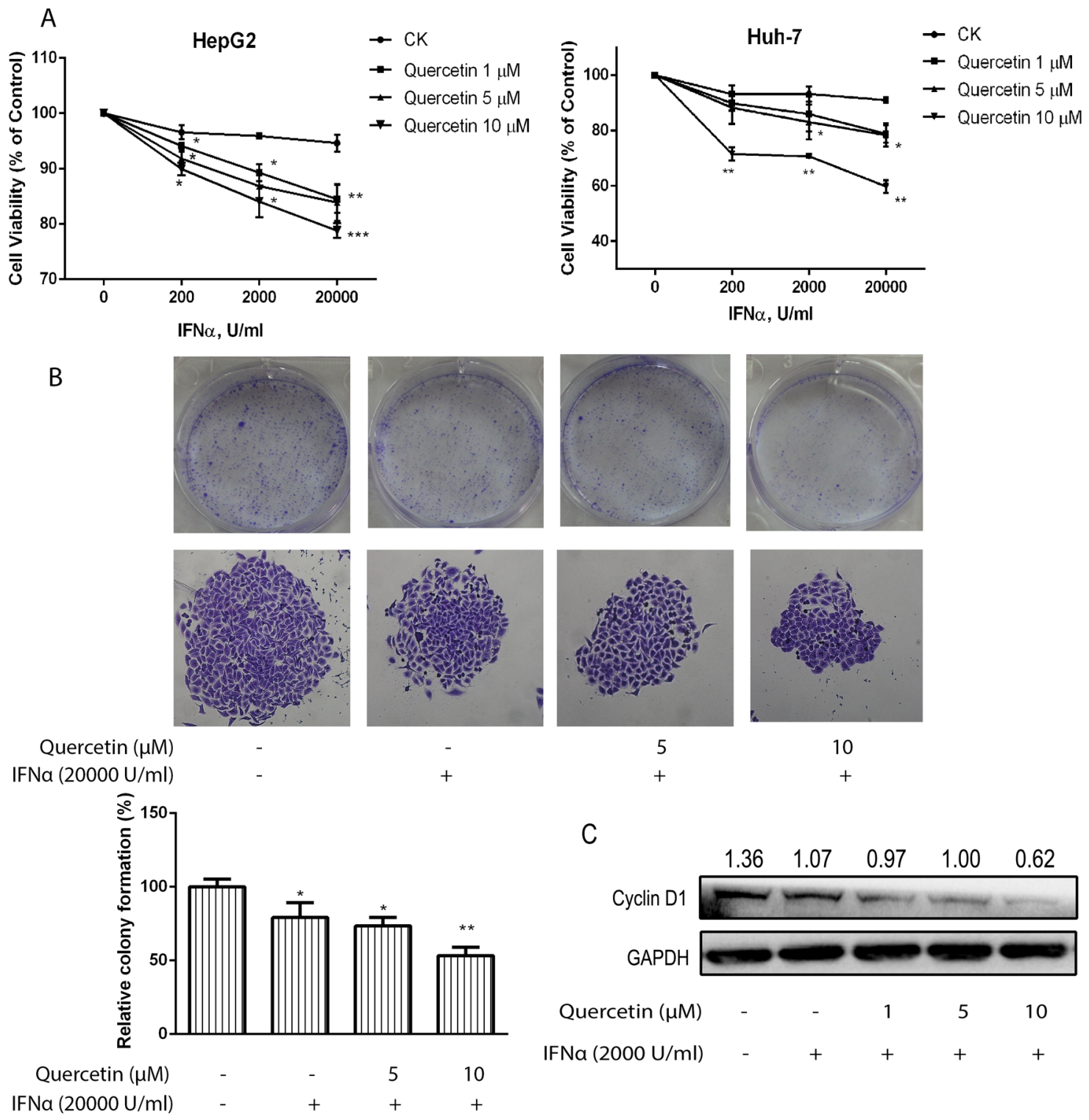

C

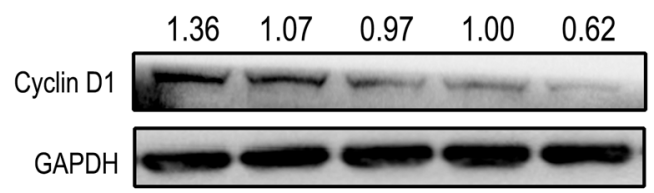

$\begin{array}{rrrrrr}\text { Quercetin }(\mu \mathrm{M}) & - & - & 1 & 5 & 10 \\ \text { IFNa }(2000 \mathrm{U} / \mathrm{ml}) & - & + & + & + & +\end{array}$

Figure 5: Quercetin enhances the inhibitory effect induced by IFN- $\boldsymbol{\alpha}$ on cancer cell viability. (A) HepG2 and Huh-7 cells were seeded in 96-well plates at $0.5 \times 10^{4}$ cells/well and treated with various concentrations of IFN- $\alpha$ and quercetin for $72 \mathrm{~h}$. Cell viability was measured using the Alamar Blue assay and the values are expressed as the percentage cell viability relative to the DMSO control. (B) HepG2 cells grown in six-well plates were treated with quercetin $(5$ and $10 \mu \mathrm{M})$ and IFN- $\alpha\left(2 \times 10^{4} \mathrm{U} / \mathrm{mL}\right)$ for 10 days and colonies were visualized by staining with crystal violet and counted manually. Data are expressed as a percentage of the colonies in the control cells and are the mean \pm S.D. of two experiments, both of which were performed in duplicate. ${ }^{*} p<0.05,{ }^{* *} p<0.01,{ }^{* * *} p<0.001$ vs control; CK, DMSO control. (C) HepG2 cells were treated with IFN- $\alpha$ and quercetin for $72 \mathrm{~h}$. The cell lysates were immunoblotted with cyclin D1 and GAPDH antibodies. 
the quercetin inhibition of SHP2, together with the potentiation of the IFN $\alpha$-induced JAK/STAT pathway signaling at low concentrations $(1-10 \mu \mathrm{M})$, heralds a novel mechanism to explain the anticancer effects of quercetin at a physiological level.

Quercetin is known to inhibit several biomarkers involved in the development of inflammation and cancers $[18,30]$. Although quercetin inhibits ERK, a key kinase in the development of inflammation and tumor, however, the mechanism responsible for this effect has not been properly elucidated $[33,34]$. The inactivation of protein phosphatase SHP2 has been known to inhibit the activation of RAS-ERK [9]. In the present study, quercetin was observed to inhibit SHP2, thus explaining its inhibitory effects on ERK activation and pro-inflammatory cytokine production. Moreover, quercetin was found to inhibit the
A

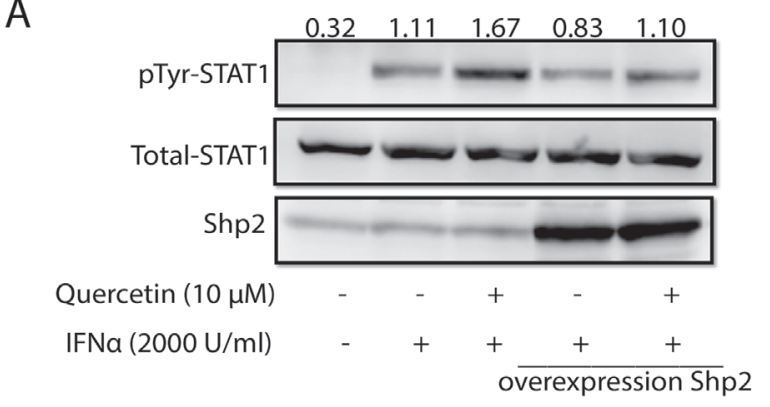

B

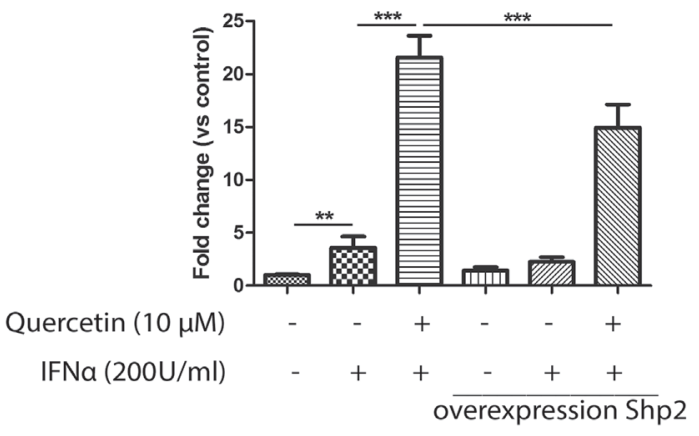

C

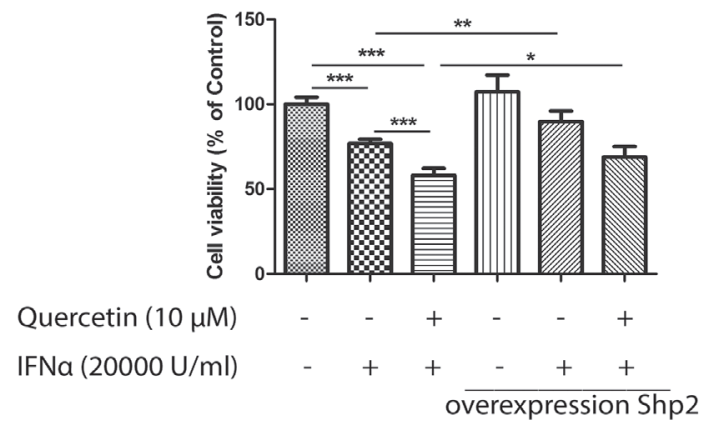

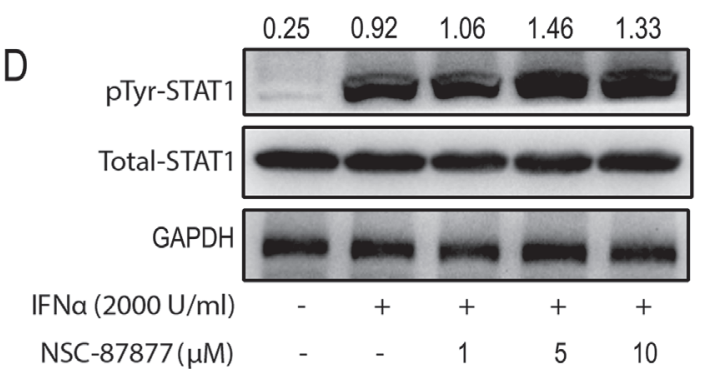

$\mathrm{E}$

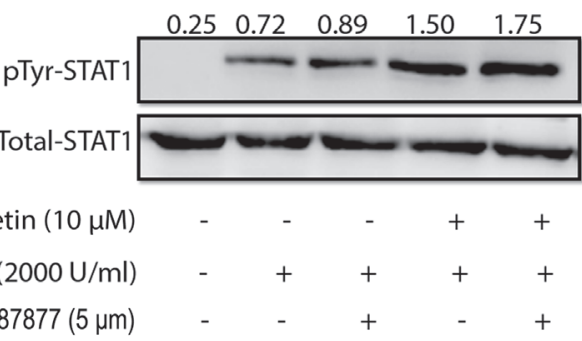

$\mathrm{F}$

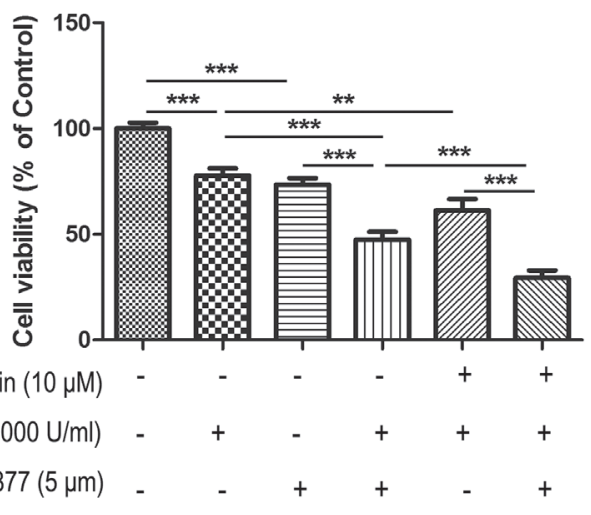

Figure 6: Quercetin increases IFN-a-induced phosphorylation of STAT1 via SHP2 inhibition. (A) HepG2 cells were transiently transfected with the empty plasmid or pCMV-SHP-2 plasmid using Trans-EZ transfection reagent, respectively. After $24 \mathrm{~h}$, the cells were treated with quercetin $(10 \mu \mathrm{M})$ for $6 \mathrm{~h}$ before the addition of $2000 \mathrm{U} / \mathrm{mL} \mathrm{IFN}-\alpha$ for $30 \mathrm{~min}$. The cell lysates were immunoblotted with phospho-STAT1 (Tyr701), STAT1, and SHP2 antibodies. (B) HepG2-ISRE-Luc2 cells were transfected with empty or SHP2 expression vectors, and then seeded in 96 -well plates $\left(1 \times 10^{4}\right.$ cells/well) and pretreated with quercetin $(10 \mu \mathrm{M})$ for $2 \mathrm{~h}$ before $200 \mathrm{U} / \mathrm{mL}$ IFN- $\alpha$ was added for a further $24 \mathrm{~h}$. The luciferase activity of the total cell lysate was measured. (C) HepG2 cells were transiently transfected with the pCMV-SHP-2 plasmid. After $24 \mathrm{~h}$, cells were seeded in 96 -well plates at $0.5 \times 10^{4}$ cells/well and treated with $20000 \mathrm{U} / \mathrm{mL}$ IFN- $\alpha$ and quercetin $(10 \mu \mathrm{M})$ for $72 \mathrm{~h}$. Cell viability was measured using the Alamar Blue assay and the values are expressed as the percentage cell viability relative to the DMSO control (mean \pm S.D). (D) HepG2 cells were pretreated with SHP2 inhibitor (NSC-87877, 1, 5, and 10 $\mu$ M) for $6 \mathrm{~h}$ before the addition of $2000 \mathrm{U} / \mathrm{mL}$ IFN- $\alpha$ for $30 \mathrm{~min}$. The cell lysates were immunoblotted with phospho-STAT1 (Tyr701) and STAT1 antibodies. (E) HepG2 were seeded in six-well plates were pretreated with quercetin $(10 \mu \mathrm{M})$ or SHP2 inhibitor (NSC-87877, $5 \mu \mathrm{M})$ for $6 \mathrm{~h}$ before the addition of $2000 \mathrm{U} / \mathrm{mL}$ IFN- $\alpha$ for $30 \mathrm{~min}$. The cell lysates were immunoblotted with phospho-STAT1 (Tyr701) and STAT1 antibodies. (F) HepG2 cells were seeded in 96 -well plates at $0.5 \times 10^{4}$ cells/well and treated with $20000 \mathrm{U} / \mathrm{mL}$ IFN- $\alpha$, quercetin $(10 \mu \mathrm{M})$, and NSC-87877 $(5 \mu \mathrm{M})$ for $72 \mathrm{~h}$. Cell viability was measured using the Alamar Blue assay and the values are expressed as the percentage cell viability relative to the DMSO control (mean \pm S.D.). ${ }^{*} p<0.05,{ }^{* *} p<0.01,{ }^{* * *} p<0.001$ vs control. 
cell growth of several human cancer types by reducing the activity and expression of proteins from the EGFR family [35]. Some studies have demonstrated the obligatory requirement of SHP2 in multiple oncogenic receptor tyrosine kinase pathways, including EGFR [36]. Cancer cell lines dependent on known receptor tyrosine kinases (such as EGFR, ERBB2, c-MET, and FLT3) were found to be sensitive to SHP2 depletion [37]. Therefore, inhibition of the SHP2 by quercetin may disturb EGFR and related oncogenic signals and increase its antitumor activity, as observed for other inhibitors of SHP2 [38]. Quercetin was shown to induce cancer cell apoptosis by increasing the stability of p53, a pivotal tumor suppressor associated with inhibition of cell proliferation; again, the mechanism of action was unclear [39-42]. Through a signaling cascade including p53, the inhibition of SHP-2 can induce the senescence and inhibition of the self-renewal of tumor cells and blockage of tumor formation and growth. Hence, the pro-apoptotic effect of quercetin on cancer cells may be attributed to its inhibition on the activity and expression of SHP2 in a p53-dependent manner.

Epidemiological studies indicate that long-term consumption of foods and vegetables rich in flavonoids reduces the risk of chronic diseases, especially cancer [43]. Quercetin, one of the most abundant dietary flavonoids, has been shown to exert several anticancer and anti-inflammatory effects. In spite of various studies that suggest the cytotoxicity of quercetin in various cancer cell lines, the mechanism of action is largely unclear [18]. In a previous report, we identified luteolin, emodin, apigenin, and quercetin as JAK/STAT pathway activators [5]. Luteolin was found to activate JAK/ STAT pathway via PKA-mediated inhibition of SHP2 [6]. Emodin and apigenin were found to activate the JAK/STAT signaling by $26 \mathrm{~S}$ proteasome inhibition and IFNAR1 stabilization [44, 45]. In this study, quercetin was further found to enhance INF- $\alpha$-induced activation of JAK/STAT signaling by direct inhibition of SHP2, which suggested that flavonoids may activate the JAK/STAT pathway through a series of distinct mechanisms. Patients receiving immunotherapies are recommended to maintain a healthy diet with a sufficient intake of vitamins and minerals to boost the functioning of the immune system, despite the potential mechanisms of this enhancement remaining largely unknown [46]. SHP2 is a key mediator of the PD-1 and BTLA immune checkpoint pathways [10]. The inactivation of the JAK/STAT pathway was associated with the acquired resistance of PD-1 blockage therapy in melanoma [47]. Currently, IFN- $\alpha / \beta$ are used in combination with conventional chemotherapeutics, targeted anticancer agents, and immunostimulatory agents such as checkpoint blockers in clinical trials [48]. Therefore, the inhibition of SHP-2 by quercetin or quercetin-rich products as a dietary supplement may be beneficial to enhance the IFN-induced anticancer effects during immunotherapy, which is a valuable topic for further study.

In conclusion, quercetin, a major constituent in dietary flavonoids, promoted the inhibitory activity of IFN- $\alpha$ on tumor cell proliferation through the JAK/STAT pathway activation by inhibition of SHP2. This study proposed a novel mechanism to explain the anticancer effects of quercetin, which necessitates further exploration as a promising adjuvant for type I IFN therapy. The consumption of quercetin or quercetin-rich products as a dietary supplement may boost the anticancer effect of type I IFNs or immune checkpoint blockers during cancer immunotherapy, which presents a worthwhile topic for further study.

\section{MATERIALS AND METHODS}

\section{Reagents and plasmids}

Quercetin was obtained from Solarbio Science \& Technology Co. Ltd (Beijing, China), the SHP2 inhibitor (NSC-87877) was obtained from Tocris Bioscience (MN, USA), and fluorogenic 6, 8-difluoro-4-methylumbelliferyl phosphate (DiFMUP) was purchased from Invitrogen (Carlsbad, CA, USA). The compounds were dissolved in dimethyl sulfoxide (DMSO; Sigma) and stored in small volume aliquots at $-20{ }^{\circ} \mathrm{C}$. IFN- $\alpha$ (recombinant human IFN- $\alpha 2 a)$ was purchased from ProSpec-Tany Techno Gene Ltd (Shanghai, China). The lyophilized protein was reconstituted in sterile water with carrier protein $(0.1 \%$ bovine serum albumin) at a concentration of $100 \mu \mathrm{g} / \mathrm{mL}$ and stored at $-80^{\circ} \mathrm{C}$. The pCMV-SHP-2 plasmid was from Fisher Scientific (Pittsburgh, PA, USA) and we obtained Trans-EZ transfection reagent from Sunbio Medical Biotechnology (Shanghai, China).

\section{Cell culture and transfection}

Human hepatocellular carcinoma cell lines (HepG2 and Huh-7) and human embryonic kidney (HEK293A) cells were purchased from Cell Bank of Chinese Academy of Science (Shanghai, China). HepG2 cells were maintained in Roswell Park Memorial Institute (RMPI; Hyclone, UT, USA) supplemented with 10\% fetal calf serum (Invitrogen) and 1\% penicillin/streptomycin. Huh-7 and HEK293A cells were maintained in Dulbecco's modified Eagle's medium (DMEM; Hyclone, UT, USA) at $37{ }^{\circ} \mathrm{C}$ in an atmosphere of $5 \% \mathrm{CO}_{2}$. The HepG2ISRE-Luc2 cell line was established and maintained as previously reported [5]. For all SHP2 overexpression experiments, transfection was performed $18 \mathrm{~h}$ following seeding. Two hours before transfection, confluent cells were cultured in fresh medium at $37^{\circ} \mathrm{C}$ for 2 hours. plasmids $(2 \mu \mathrm{g} / \mathrm{mL})$ were transfected into cells by using Trans-EZ transfection reagent. After $6 \mathrm{~h}$, the transfection 
complex was replaced with fresh medium. The transfected cells were then used for subsequent studies after $24 \mathrm{~h}$.

\section{Luciferase reporter assay}

HepG2-ISRE-Luc2 cells were seeded at $1 \times 10^{4}$ cells/ well in 96-well plates and incubated for $24 \mathrm{~h}$. The cells were pretreated with various concentrations of quercetin for $2 \mathrm{~h}$ and then $200 \mathrm{U} / \mathrm{mL} \mathrm{IFN-} \alpha$ was added for a further $24 \mathrm{~h}$. The luciferase activity of the total cell lysate was measured using a Luciferase Reporter Assay System (Promega) in accordance with the manufacturer's instructions. The luminescence intensity was measured by using a Thermo Scientific Varioskan ${ }^{\circledR}$ Flash (Thermo Scientific, USA).

\section{Western blot analysis}

After treatment, the cells were harvested in RIPA buffer supplemented with a protease inhibitor cocktail (Sigma, Shanghai, China). The protein concentration was measured by using a BCA protein assay kit (Bestbio, Shanghai, China). Aliquots of total cell lysates (50 $\mu \mathrm{g}$ protein) were mixed with loading buffer, boiled for $5 \mathrm{~min}$, and separated on a $10 \%$ sodium dodecyl sulfate (SDS)-polyacrylamide gel. After electrophoresis, the proteins were transferred to nitrocellulose membranes. The membranes were blocked with $5 \%$ bovine serum albumin or $5 \%$ de-fatted milk powder for $1 \mathrm{~h}$ at room temperature and then incubated overnight at $4{ }^{\circ} \mathrm{C}$ with each of the following antibodies: anti-phospho-STAT1 (SAB Signalway Antibody, College Park, MD, USA), antiSTAT1 (Proteintech, IL, USA), anti-phospho-STAT2 (SAB), anti-STAT2 (Proteintech), anti-phospho-STAT3 (SAB), anti-STAT3 (Proteintech), anti-SOCS1 (Proteintech), antiSOCS3 (Proteintech), anti-SHP1 (Proteintech), anti-SHP2 (Proteintech), anti-GAPDH (Huabio, Hangzhou, China), anti-Jak1 (SAB), anti-phospho-Jak1 (SAB), anti-Tyk2 (Proteintech), and anti-phospho-Tyk2 (SAB). Thereafter, the membranes were incubated with an appropriate peroxidase-conjugated secondary antibody. The presence of the secondary antibody was determined by the detection of enhanced chemiluminescence solution (Amersham Biosciences, Piscataway, NJ, USA).

\section{Immunoprecipitation}

HEK293A cells were lysed in RIPA buffer that contained a complete protease inhibitor mixture and phosphatase after treatment with quercetin and SHP2 inhibitor (NSC-87877) for $6 \mathrm{~h}$. The lysates were incubated on ice for $10 \mathrm{~min}$ and centrifuged at $20,000 \times g$ for 15 min at $4{ }^{\circ} \mathrm{C}$. Cleared lysates were incubated with SHP2 antibody overnight at $4{ }^{\circ} \mathrm{C}$ with agitation, followed by precipitation of antibody-antigen complexes with protein A/G-agarose (Santa Cruz Biotech, TX, USA). The immunoprecipitates were washed three times and then the complexes were resuspended gently in reaction buffer $(100 \mu \mathrm{L})$ and transferred to a 96-well plate.

\section{Recombinant SHP2 expression and activity assay}

The plasmid for the expression of glutathione S-transferase (GST)-SHP2 (residues 205-593) fusion protein was constructed in pGEX-4T-1 (Madison WI, USA) by using PCR subcloning techniques. The recombinant plasmid was verified by DNA sequencing. The vector was transformed into Escherichia coli BL21 and grown overnight in LB medium $(300 \mathrm{~mL})$ containing ampicillin $(100 \mathrm{mg} / \mathrm{L})$. Once the culture reached an OD600 of 0.6, protein expression was induced by the addition of $1 \mathrm{mM}$ isopropyl $\beta$-D-1-thiogalactopyranoside (IPTG) to the culture, which was then maintained for $4 \mathrm{~h}$ at $37^{\circ} \mathrm{C}$. Cells were pelleted by centrifugation for $20 \mathrm{~min}$ at $10,000 \times \mathrm{g}$ and resuspended in PBS $(20 \mathrm{~mL})$ containing lysozyme and phenylmethanesulfonyl fluoride. The clarified lysate was then filtered through a $45-\mu \mathrm{m}$ syringe filter and affinity purified with glutathione-Sepharose. GST-SHP2 was eluted from the column with $3 \mathrm{~mL}$ elution buffer (50 mM Tris-HCl, pH 8.0, $10 \mathrm{mM}$ glutathione, 2 $\mathrm{mM}$ EDTA, and $2 \mathrm{mM}$ DTT) and $500 \mu \mathrm{L}$ fractions were collected. The fractions containing the highest SHP-2 activity were pooled and dialyzed against dialysis buffer (10 mM Tris-HCl, pH 7.5, 1 mM EDTA, 2 mM DTT, $30 \%$ glycerol) overnight using a 3500 MWCO Slide-ALyzer Dialysis Cassette (Thermo Fisher Scientific, USA). Recombinant SHP1 was purchased from Sino Biological (Beijing, China).

SHP2 and SHP1 activities were measured using the fluorogenic DiFMUP as the substrate. Each reaction included $5 \mu \mathrm{L}$ of the test compound or DMSO (solvent) and the reaction buffer, which contained $25 \mathrm{mM}$ MOPS, pH 7.0, $50 \mathrm{mM} \mathrm{NaCl}, 0.05 \%$ Tween 20, $1 \mathrm{mM}$ DTT, 20 $\mu \mathrm{M}$ DiFMUP, $10 \mathrm{nM}$ Microcystin LR, and $20 \mathrm{nM}$ SHP2 protein, in a total volume of $100 \mu \mathrm{L}$, in black 96-well plates. The reaction was initiated by the addition of DiFMUP and incubated for $30 \mathrm{~min}$ at $37^{\circ} \mathrm{C}$. The DiFMUP fluorescence signal was measured at an excitation wavelength of 355 $\mathrm{nm}$ and an emission wavelength of $460 \mathrm{~nm}$ with a plate reader (Thermo Scientific Varioskan ${ }^{\circledR}$ Flash). The $\mathrm{IC}_{50}$ was defined as the concentration of an inhibitor that caused a $50 \%$ decrease in enzyme activity. Determination of the $\mathrm{IC}_{50}$ was conducted following the measurement of six concentrations of quercetin. The ranges of quercetin concentrations used in each activity assay were determined from preliminary trials. Each experiment was performed in triplicate, and the $\mathrm{IC}_{50}$ data were derived from at least three independent experiments. The curve-fitting program Prism 4 (GraphPad Software, San Diego, CA, USA) was used to calculate the $\mathrm{IC}_{50}$ values.

\section{Cellular thermal shift assay}

HEK293A cells were harvested and diluted in PBS supplemented with complete protease inhibitor cocktail. The cell suspensions were freeze-thawed three times with liquid nitrogen and the soluble fraction (the lysate) was 
separated from the cell debris by centrifugation at 20,000 $\times g$ for $20 \mathrm{~min}$ at $4{ }^{\circ} \mathrm{C}$. The cell lysates were diluted with PBS and divided into two aliquots; one aliquot was treated with DMSO and the other aliquot was treated with quercetin $(100 \mu \mathrm{M})$. Both aliquots were incubated for $30 \mathrm{~min}$ at room temperature, and then subsequently divided into $50-\mu \mathrm{L}$ aliquots and heated individually at different temperatures for 3 min (Eppendorf Mastercycler, Hamburg) followed by a cooling period of $3 \mathrm{~min}$. The appropriate temperatures were determined in preliminary experiments (data not shown). The heated lysates were centrifuged at $20,000 \times g$ for $20 \mathrm{~min}$ at $4{ }^{\circ} \mathrm{C}$ in order to separate the soluble fractions from the precipitates. The supernatants were dissolved in loading buffer, boiled for 5 min, separated by sodium dodecyl sulfate polyacrylamide gel electrophoresis (SDS-PAGE) and analyzed by western blotting. The dose effect of quercetin on the stability of SHP2 and vinculin were evaluated in the same manner.

\section{Computational binding simulation}

Molecular docking was simulated as described below. Briefly, the 3D crystal structure of SHP2 was downloaded from Protein Data Bank (www.rcsb.org) with the PDB code 3B7O (PTPN11, SHP2 D1). This crystal structure has an accessible active site without the N-SH2 and C-SH2 domains. The crystal structure information of quercetin was obtained from a previous report [49]. The structures of SHP2 and quercetin were then prepared using AutoDockTools by removing the bond disorder, adding hydrogen, and deleting water. Docking simulations were carried out with Autodock 4.2.6 and AutodockVina 1.1.2. Docking was performed sequentially in two steps. Initially, a large grid map to cover the whole protein was used to perform blind docking with a grid-point spacing of $0.2 \AA$. Then, the second step involved localized docking with a smaller grid box $(20 \AA \times 20 \AA \times 20 \AA)$ centered at the potential binding site of interest, which included the active site and the allosteric site. For Autodock, the docking calculation was performed using the Lamarckian genetic algorithm with default parameters. Cluster analysis was conducted to assess the optimal binding pose of the ligands. For AutodockVina, the default parameters were also used. The docking results were predicted based on the binding energy and the inhibition constant. Additionally, a schematic plan of ligand interactions showing hydrogen bonds and hydrophobic interactions were visualized by LigPlot+. Finally, images were rendered with PyMOL 1.5.0.4 and the best pose was used to calculate the hydrogen bond distances, which were measured between the hydrogen and its assumed binding partner.

\section{Quantitative real-time reverse transcription- polymerase chain reaction (qRT-PCR)}

Total cellular RNA was isolated from treated HepG2 cells using TRIzol reagent (Invitrogen) in accordance with the manufacturer's protocol. Total RNA was reverse- transcribed using SuperScript III Reverse Transcriptase (Invitrogen) with oligo dT18 primer. Equal amounts of cDNA were subjected to real-time quantitative PCR with the fluorescent dye SYBR Green I in accordance with the manufacturer's protocol (TransGen Biotech, Beijing, China). The primer pairs used in the assay for interferoninduced double-stranded RNA-activated protein kinase (PKR), 2',5'-oligoadenylate synthetase (2',5-OAS), and glyceraldehyde-3-phosphate dehydrogenase (GAPDH) were as follows: PKR, 5'-GTT TGC TTC TCT GGC GGT CTT-3' (forward), 5'-GCC ATT TCT TCT TCC CGT ATC C-3' (reverse); 2',5'-OAS, 5'-AGG TGG TAA AGG GTG GCT CC-3' (forward), 5'-ACA ACC AGG TCA GCG TCA GAT-3' (reverse); and GAPDH, 5'-TGC ACC ACC AAC TGC TTA GC-3' (forward), 5'-GGC ATG GAC TGT GGT CAT GAG-3' (reverse). The samples were run in triplicate and the relative expression levels of PKR and 2',5'-OAS were determined by normalizing the expression of each target gene to that of GAPDH using the $2^{-\Delta \Delta \mathrm{Ct}}$ method.

\section{Cell viability assay}

HepG 2 and Huh- 7 cells were plated at $5 \times 10^{3}$ cells/ well in 96-well plates in $100 \mu \mathrm{L}$ medium. The cultured cells were then treated with various concentrations of quercetin or a combination of quercetin and IFN- $\alpha$. After $72 \mathrm{~h}, 10 \mu \mathrm{L}$ of Alamar Blue reagent (SunBio Medical Biotechnology, Shanghai, China) was added to the medium and incubated for 2-4 h until the blue color changed to pink. The relative fluorescence intensity in each well was measured using a Varioskan ${ }^{\circledR}$ Flash.

\section{Colony formation assay}

HepG2 cells (200 cells/well) were seeded in six-well plates, treated with quercetin in combination with IFN- $\alpha$, and allowed to grow for 10 days to form colonies. The cell colonies were then fixed with methanol at $4{ }^{\circ} \mathrm{C}$ for $20 \mathrm{~min}$ and stained with crystal violet $\left(0.1 \%\right.$ in $\left.\mathrm{H}_{2} \mathrm{O}\right)$ for $5 \mathrm{~min}$. The plates were rinsed with water, air-dried, photographed, and evaluated for colony formation. Colonies containing more than 50 cells were counted.

\section{Statistical analysis}

Statistical analyses were performed with GraphPad Prism 5.0 software (GraphPad, La Jolla, CA, USA). All experiments were repeated at least three times and representative results were presented. The data were compared by one-way ANOVA followed by Dunnett's post-hoc test. Differences were considered statistically significant for values of $\mathrm{p}<0.05$.

\section{Abbreviations}

2'5'-OAS, 2'-5' -oligoadenylate synthetase; DiFMUP, 6, 8-difluoro-4-methylumbelliferyl phosphate; EGFR, epidermal growth factor receptor; IFN, interferon; 
IFNAR, interferon- $\alpha / \beta$ receptor; ISRE, interferonsensitive response element; JAK, janus kinase; PIAS, protein inhibitors of activated STAT; PKA, protein kinase A; PKR, protein kinase R; SHP2, Src homology domain 2 containing tyrosine phosphatase-2; SOCS, suppressor of cytokine signaling; STAT, signal transducer and activator of transcription.

\section{ACKNOWLEDGMENTS}

This work was supported by the National Natural Science Foundation of China (No. 21561142003, 21672207, 21672205), Science \& Technology Department of Sichuan Province (No. 2016JZ0022), Chinese Academy of Sciences President's International Fellowship Initiative (No. 2015PB049), the National New Drug Innovation Major Project of China (2017ZX09101003-001-006), and Research Foundation of State General Administration of The People's Republic of China for Quality Supervision and Inspection and Quarantine (No. 2015IK180).

\section{CONFLICTS OF INTEREST}

The authors have declared no conflicts of interest.

\section{REFERENCES}

1. Lengyel P. Biochemistry of interferons and their actions. Annu Rev Biochem. 1982; 51:251-282.

2. Borden EC, Sen GC, Uze G, Silverman RH, Ransohoff RM, Foster GR, Stark GR. Interferons at age 50: Past, current and future impact on biomedicine. Nat Rev Drug Discov. 2007; 6:975-990.

3. Jonasch E, Haluska FG. Interferon in oncological practice: Review of interferon biology, clinical applications, and toxicities. Oncologist. 2001; 6:34-55.

4. Konishi H, Okamoto K, Ohmori Y, Yoshino H, Ohmori H, Ashihara M, Hirata Y, Ohta A, Sakamoto H, Hada N, Katsume A, Kohara M, Morikawa K, et al. An orally available, small-molecule interferon inhibits viral replication. Sci Rep. 2012; 2:259.

5. Tai ZF, Zhang GL, Wang F. Identification of small molecule activators of the janus kinase/signal transducer and activator of transcription pathway using a cell-based screen. Biol Pharm Bull. 2012; 35:65-71.

6. Tai ZF, Lin Y, He YJ, Huang JM, Guo JJ, Yang LJ, Zhang GL, Wang F. Luteolin sensitizes the antiproliferative effect of interferon $\alpha / \beta$ by activation of janus kinase/signal transducer and activator of transcription pathway signaling through protein kinase A-mediated inhibition of protein tyrosine phosphatase SHP-2 in cancer cells. Cell Signal. 2014; 26:619-628.

7. Grossmann KS, Rosário M, Birchmeier C, Birchmeier W. The tyrosine phosphatase Shp2 in development and cancer. Adv Cancer Res. 2010; 106:53-89.
8. Mohi MG, Neel BG. The role of Shp2 (PTPN11) in cancer. Curr Opin Genet Dev. 2007; 17:23-30.

9. Matozaki T, Murata Y, Saito Y, Okazawa H, Ohnishi H. Protein tyrosine phosphatase SHP-2: a proto-oncogene product that promotes Ras activation. Cancer Sci. 2009; 100:1786-1793.

10. Yokosuka T, Takamatsu M, Kobayashi-Imanishi W, Hashimoto-Tane A, Azuma M, Saito T. Programmed cell death 1 forms negative costimulatory microclusters that directly inhibit $\mathrm{T}$ cell receptor signaling by recruiting phosphatase SHP2. J Exp Med. 2012; 209:1201-1217.

11. Shuai K, Liu B. Regulation of JAK-STAT signaling in the immune system. Nat Rev Immunol. 2003; 3:900-911.

12. You M, Yu DH, Feng GS. Shp-2 tyrosine phosphatase functions as a negative regulator of the interferon-stimulated Jak/STAT pathway. Mol Cell Biol. 1999; 19:2416-2424.

13. Wu TR, Hong YK, Wang XD, Ling MY, Dragoi AM, Chung AS, Campbell AG, Han ZY, Feng GS, Chin YE. SHP-2 is a dual-specificity phosphatase involved in Stat1 dephosphorylation at both tyrosine and serine residues in nuclei. J Biol Chem. 2002; 277:47572-47580.

14. Knekt $\mathrm{P}$, Kumpulainen J, Järvinen R, Rissanen $\mathrm{H}$, Heliövaara M, Reunanen A, Hakulinen T, Aromaa A. Flavonoid intake and risk of chronic diseases. Am J Clin Nutr. 2002; 76:560-568.

15. Hakkinen SH, Karenlampi SO, Heinonen IM, Mykkanen HM, Torronen AR. Content of the flavonols quercetin, myricetin, and kaempferol in 25 edible berries. J Agric Food Chem. 1999; 47:2274-2279.

16. Casella ML, Parody JP, Ceballos MP, Quiroga AD, Ronco MT, Frances DE, Monti JA, Pisani GB, Carnovale CE, Carrillo MC, de Lujan Alvarez M. Quercetin prevents liver carcinogenesis by inducing cell cycle arrest, decreasing cell proliferation and enhancing apoptosis. Mol Nutr Food Res. 2014; 58:289-300.

17. Granado-Serrano AB, Martin MA, Bravo L, Goya L, Ramos S. Quercetin induces apoptosis via caspase activation, regulation of Bcl-2, and inhibition of PI-3-kinase/Akt and ERK pathways in a human hepatoma cell line (HepG2). J Nutr. 2006; 136:2715-2721.

18. Murakami A, Ashida H, Terao J. Multitargeted cancer prevention by quercetin. Cancer Lett. 2008; 269:315-325.

19. Jafari R, Almqvist H, Axelsson H, Ignatushchenko M, Lundbäck T, Nordlund P, Molina DM. The cellular thermal shift assay for evaluating drug target interactions in cells. Nat Protoc. 2014; 9:2100-2122.

20. Jung JH, Lee JO, Kim JH, Lee SK, You GY, Park SH, Park JM, Kim EK, Suh PG, An JK, Kim HS. Quercetin suppresses HeLa cell viability via AMPK-induced HSP70 and EGFR down-regulation. J Cell Physiol. 2010; 223:408-414.

21. Darian E, Guvench O, Yu B, Qu CK, MacKerell AD. Structural mechanism associated with domain opening in 
gain-of-function mutations in SHP2 phosphatase. Proteins. 2011; 79:1573-1588.

22. Merritt R, Hayman MJ, Agazie YM. Mutation of Thr466 in SHP2 abolishes its phosphatase activity, but provides a new substrate-trapping mutant. Biochim Biophys Acta. 2006; 1763:45-56.

23. Tajan M, de Rocca Serra A, Valet P, Edouard T, Yart A. SHP2 sails from physiology to pathology. Eur J Med Genet. 2015; 58:509-525.

24. Chen LW, Sung SS, Yip MR, Lawrence HR, Ren Y, Guida WC, Sebti SM, Lawrence NJ, Wu J. Discovery of a novel shp2 protein tyrosine phosphatase inhibitor. Mol Pharmacol. 2006, 70, 562-570.

25. Kontaridis MI, Swanson KD, David FS, Barford D, Neel BG. PTPN11 (Shp2) mutations in LEOPARD syndrome have dominant negative, not activating, effects. J Biol Chem. 2006; 281:6785-6792.

26. Richman DD. Antiviral drug resistance. Antiviral Res. 2006; 71:117-121.

27. Lin Y, Wang F, Zhang GL. Natural products and their derivatives regulating the janus kinase/signal transducer and activator of transcription pathway. J Asian Nat Prod Res. 2014; 16:800-812.

28. Domanska D, Brzezianska E. The JAK/STAT protein activation: role in cancer development and targeted therapy. Curr Signal Transduct Ther. 2012; 7:187-201.

29. Croker BA, Kiu H, Nicholson SE. SOCS regulation of the JAK/STAT signalling pathway. Semin Cell Dev Biol. 2008; 19:414-422.

30. Russo M, Spagnuolo C, Tedesco I, Bilotto S, Russo GL. The flavonoid quercetin in disease prevention and therapy: facts and fancies. Biochem Pharmacol. 2012; 83:6-15.

31. Shiratori Y, Shiina S, Teratani T, Imamura M, Obi S, Sato S, Koike Y, Yoshida H, Omata M. Interferon therapy after tumor ablation improves prognosis in patients with hepatocellular carcinoma associated with Hepatitis C virus. Ann Intern Med. 2003; 138:299-306.

32. Han T, Xiang DM, Sun W, Liu N, Sun HL, Wen W, Shen WF, Wang RY, Chen C, Wang X, Cheng Z, Li HY, Wu MC, et al. PTPN11/Shp2 overexpression enhances liver cancer progression and predicts poor prognosis of patients. J Hepatol. 2015; 63:651-660.

33. Nguyen TTT, Tran E, Nguyen TH, Do PT, Huynh TH, Huynh H. The role of activated MEK-ERK pathway in quercetin-induced growth inhibition and apoptosis in A549 lung cancer cells. Carcinogenesis. 2004; 25:647-659.

34. Cho SY, Park SJ, Kwon MJ, Jeong TS, Bok SH, Choi WY, Jeong WI, Ryu SY, Do SH, Lee CS, Song JC, Jeong SK. Quercetin suppresses proinflammatory cytokines production through MAP kinases and NF- $\kappa$ B pathway in lipopolysaccharide-stimulated macrophage. Mol Cell Biochem. 2003; 243:153-160.
35. Bhat FA, Sharmila G, Balakrishnan S, Arunkumar R, Elumalai P, Suganya S, Singh R, Srinivasan N, Arunakaran J. Quercetin reverses EGF-induced epithelial to mesenchymal transition and invasiveness in prostate cancer (PC-3) cell line via EGFR/PI3K/Akt pathway. J Nutr Biochem. 2014; 25:1132-1139.

36. Stommel JM, Kimmelman AC, Ying H, Nabioullin R, Ponugoti AH, Wiedemeyer R, Stegh AH, Bradner JE, Ligon KL, Brennan C, Chin L, DePinho RA. Coactivation of receptor tyrosine kinases affects the response of tumor cells to targeted therapies. Science. 2007; 318:287-290.

37. Chen YN, LaMarche MJ, Chan HM, Fekkes P, GarciaFortanet J, Acker MG, Antonakos B, Chen CH, Chen ZL, Cooke VG, Dobson JR, Deng Z, Fei F, et al. Allosteric inhibition of SHP2 phosphatase inhibits cancers driven by receptor tyrosine kinases. Nature. 2016; 535:148-152.

38. Schneeberger VE, Ren Y, Luetteke N, Huang QL, Chen LW, Lawrence HR, Lawrence NJ, Haura EB, Koomen JM, Coppola D, Wu J. Inhibition of Shp2 suppresses mutant EGFR-induced lung tumors in transgenic mouse model of lung adenocarcinoma. Oncotarget. 2015; 6:6191-6202. https://doi.org/10.18632/oncotarget.3356.

39. Kuo PC, Liu HF, Chao J. Survivin and p53 modulate quercetin-induced cell growth inhibition and apoptosis in human lung carcinoma cells. J Biol Chem. 2004; 279:55875-55885.

40. Tanigawa S, Fujii M, Hou DX. Stabilization of p53 is involved in quercetin-induced cell cycle arrest and apoptosis in HepG2 cells. Biosci Biotechnol Biochem. 2008; 72:797-804.

41. Vidya Priyadarsini R, Senthil Murugan R, Maitreyi S, Ramalingam K, Karunagaran D, Nagini S. The flavonoid quercetin induces cell cycle arrest and mitochondriamediated apoptosis in human cervical cancer (HeLa) cells through p53 induction and NF- $\kappa \mathrm{B}$ inhibition. Eur $\mathrm{J}$ Pharmacol. 2010; 649:84-91.

42. Lan LX, Holland JD, Qi JJ, Grosskopf S, Vogel R, Györffy B, Wulf-Goldenberg A, Birchmeier W. SHP2 signaling suppresses senescence in PyMT-induced mammary gland cancer in mice. EMBO J. 2015; 34:1493-1508.

43. Xiao ZP, Peng ZY, Peng MJ, Yan WB. Ouyang YZ, Zhu HL. Flavonoids health benefits and their molecular mechanism. Mini Rev Med Chem. 2011; 11:169-177.

44. He YJ, Huang JM, Wang P, Shen XF, Li S, Yang LJ, Liu WL, Suksamrarn A, Zhang GL, Wang F. Emodin potentiates the antiproliferative effect of interferon $\alpha / \beta$ by activation of JAK/STAT pathway signaling through inhibition of the 26S proteasome. Oncotarget. 2016; 7:4664-4679. https://doi.org/10.18632/oncotarget.6616.

45. Li S, Yang LJ, Wang P, He YJ, Huang JM, Liu HW, Shen XF, Wang F. Dietary apigenin potentiates the inhibitory effect of interferon- $\alpha$ on cancer cell viability through 
inhibition of $26 \mathrm{~S}$ proteasome-mediated interferon receptor degradation. Food Nutr Res. 2016; 60:31288.

46. Pitt JM, Vétizou M, Daillère R, Roberti MP, Yamazaki T, Routy B, Lepage P, Boneca IG, Chamaillard M, Kroemer G, Zitvogel L. Resistance mechanisms to immune checkpoint blockade in cancer: tumor-intrinsic and- extrinsic factors. Immunity. 2016; 44:1255-1269.

47. Zaretsky JM, Garcia-Diaz A, Shin DS, Escuin-Ordinas H, Hugo W, Hu-Lieskovan S, Torrejon DY, Abril-Rodriguez G, Sandoval S, Barthly L, Saco J, Moreno BH, Mezzadra R, et al. Mutations associated with acquired resistance to PD-1 blockade in melanoma. N Engl J Med. 2016; 375:819-829.

48. Zitvogel L, Galluzzi L, Kepp O, Smyth MJ, Kroemer G. Type I interferons in anticancer immunity. Nat Rev Immunol. 2015; 15:405-414.

49. Domagała S, Munshi P, Ahmed M, Guillot B, Jelsch C. Structural analysis and multipole modelling of quercetin monohydrate-a quantitative and comparative study. Acta Crystallogr B. 2011; 67:63-78. 